\title{
DRIVING FORWARD TECHNOLOGY'S IMPRINT ON MUSIC EDUCATION
}

\author{
JONATHAN SAVAGE
}

It is always wise to look ahead, but difficult to look further than you can see.

This quotation from Winston Churchill is apposite for a chapter that seeks to draw together what has preceded it, amplify its themes, and use them to anticipate future dispositions towards the application of music technology in education settings. In many educational contexts around the world the use of music technologies has increased rapidly. As the previous chapters within this part of the handbook have considered, there have been significant pieces of research related to curriculum design, teacher pedagogy, and ways of learning with technology. Many of these have impacted on the work of music educators in positive ways. But this is not a time for self-congratulation or passive reflection. Outside the often-closeted world of education, technological developments continue to move forwards rapidly. Hardly a week goes by without comment in the international press about a new technological innovation or application related to the production, reception, or consumption of music in one form or another.

Recently, issues such as the establishment of an agency for navigating online copyright issues for film and musical content has been discussed (Fitzsimmons, 2009), new systems to help train people to use prosthetic limbs using Guitar Hero (a 
music video game) have been developed (Graham, 2009), and iPhone, iPod Touch, and iPad owners have seen the development of a plethora of applications to play virtual pianos, drums, and guitars (Apple, 2009). As developments in technology move relentlessly forwards, there are the twin dangers facing educators: moving too quickly or too slowly. Either way, disjunctions between the pedagogy and practice of music education have been noted, in school-based education (Savage, 2004, p.167; Cain, 2004, p. 217; Ofsted, 2009, p. 34) and higher education (Draper, 2008, p. 137; Jenkins et al., 2007, p. 129). Now, more than ever, music educators need to be maintain their focus on what constitutes effective teaching and learning with music technology. If, in Churchill's words, "it is wise to look ahead but difficult to look further than one can see," what methods or tools could we utilize to help us do this more effectively?

\section{Key Principles}

Establishing principles for educational change is a tricky and problematic task. In the majority of this chapter we will be looking ahead at the challenges we may face, using key principles drawn from a piece of educational research. Before we do that, we will briefly look backward and reflect on how we have got to where we are today.

\section{LOOKING BACKWARD}

Technology has permeated every aspect of our musical lives in the early twentyfirst century. They provide us with new opportunities to listen to music, to produce, share, and perform musical ideas together, and to teach and learn from one another. The use of technology within music education has challenged and reshaped views about the principles and purposes of music teaching and learning. As an example, Reimer's question about the importance of musical performance as a central role in a music education remains as important today as it did when it was first posed (Reimer, 1994; Savage, 2005a). The precise skills, embodied knowledge, or understanding that the activity of musical performance actually facilitates is worth debating.Within the United Kingdom this is something that is currently receiving considerable attention, as approaches to whole-class instrumental teaching, such as Wider Opportunities, are embedded across the country. The perceived benefits of this on students' self-esteem and wider academic studies are easily written about in evaluative studies (FMS, 2010) but perhaps less easy to substantiate, due to a lack of longitudinal studies in these areas (Savage, 2010a).

More generally, technology leaves its mark on our work and in our minds; its imprint becomes firmly embedded on our pedagogies, implicating our thinking in implicit and explicit ways. Once there, it is hard to remove, and the nature of 
our responses to it have shaped the nature of music education to this point in time. Some readers may feel that their work has "escaped" the technological imprint up to this point. I would gently like to question this assumption. Many young people's experience of music outside the formal learning context is technologically rich and varied. Musical learning in the "real" world, outside the formality of schools and classrooms, is often portrayed as transparent and boundless when compared to the formal classroom. Without the prevailing subject cultures and unhelpful categorizations of knowledge and pedagogy that dominate our schools, in the "real" world learners can navigate their way seamlessly among and between subject knowledge that, the argument goes, they might find more difficult to achieve in a more formal setting. Of course, such bald parallels are based on false assumptions and a narrow understanding of what happens within both contexts. But the intelligent use and application of music technologies has provided us with an opportunity to challenge our way of thinking about subjects, curricula, teaching, and learning. Has this discourse really passed teachers by? To what extent has their work successfully responded to the technology's imprint on the musical lives of their students?

The challenge of responding positively to this imprint on our work is not easy. There are many strong forces that militate against it. One of the restraining elements is a strong, traditional view of music within a particular subject culture. For Goodson and Mangen, a "subject culture" (Goodson \& Mangen, 1998, p.120) is"an identifiable structure which is visibly expressed through classroom organization and pedagogical styles." For many teachers, the subject culture and its associated"ways of being" (Van Manen, 1977, p. 205) define their teaching practice at a fundamental level. Within the secondary education context, the opportunity to develop one's subject and teach others about it is high up the list of most teachers' job satisfaction (Spear, Gould, \& Lea, 2000, p. 52). Within initial teacher education, subject knowledge (i.e., the actual knowledge of the subject but also, implicitly, the way that the subject is presented and traditionally taught) is a strong, formative force on the beginner teacher. It can consolidate and congeal approaches to teaching and learning if an uncritical stance is allowed to develop. Young teachers need to cultivate a deliberate sense of"playful engagement" with their formative subject culture. The critical and reflective teacher of music has stood a better chance of responding positively to the technological imprint when they have been able to reconceptualize music's subject culture to accommodate new technology mediated musical practices.

As we change our focus and begin to look forward, the following key principles will give the reader a stronger chance of engaging in a constructive way to future technological developments within music education.

\section{LOOKING FORWARDS}

Looking forwards, what key principles could underpin our work in developing the use of music technology as a tool for teaching and learning? "Futures" research in education provides us with some starting points. One of the most extensive pieces 
of research into the future of education and technology was recently completed in the United Kingdom. Beyond Current Horizons was a two-year project funded by the Department for Children, Schools and Families which drew together over 100 academics from disciplines as diverse as computer science, demography, psychology, and sociology of childhood, and involved contributions from over 130 other organizations and individuals from industry, practice, policy, and research. The aim of the Beyond Current Horizons research project was

to explore the potential futures for education that might emerge at the intersection of social and technological change over the coming two decades. Its purpose is to map out current and emerging socio-technical trends, the critical uncertainties in our understanding of future socio-technical developments, and the challenges or opportunities that such developments might offer to educators. (DCSF \& Futurelab, 2009, p. 3)

In order to assist its research methodology, the Beyond Current Horizons program developed four principles that built on a review of the existing fields of futures research and educational futures, theoretical gains from social studies of technology, and insights from educational philosophy. These four principles provide a useful starting point for our discussion with respect to the future of music technologies in education. Each will be briefly considered and applied.

1. Our aim today is to challenge assumptions rather than present definitive predictions.

Researching the future cannot simply be a case of producing a set of predictions of what "will happen" as though this were beyond the intervention of individuals or societies. Nor can it simply be a case of discussing what we "want" or "will make" happen, as though there were no prior contexts to shape our actions. (Facer \& Sandford, 2010, p. 76)

A key element of imagining future educational scenarios is about challenging assumptions today and using these to ask questions about potential future models. Facer, the program director, quotes Bell, who proposed that futures research can best be understood as an attempt to explore the relationships between "possible, probable, and preferable" futures. This involves asking "what can or could be (the possible), what is likely to be (the probable), and what ought to be (the preferable)?" (Bell, 1997, p. 73). But prior to seeking answers to these questions, the first task of any exploration of the possible futures for music technology within education must be to critique the assumption that there is an inevitable future to which we must simply adapt or resist.

Within the context of our work as music educators, remember that any imagined future curriculum models for music, or any new technologies that may be invented or applied to our work, are similarly contextualized by assumptions, contexts, and actions, the majority of which are known to us today. Bell's questions in the above paragraph are as relevant to proposed musical developments as they are to generic models for the future uses of technology in education. Critiquing our assumptions, our actions, our pedagogies as music educators today are vital first steps. Maintaining a questioning and enquiring mindset should underpin all our work. 
But there are a number of dangers here. Firstly, assuming that change will not happen. This is naïve. Technological change is apparent, obvious, and surrounds us each day. Secondly, assuming that change will happen more quickly than it does. This is equally unhelpful. The history of technology is littered with unfulfilled assumptions and overly positivistic rhetoric. Many of these obscure and complicate our thinking at a time when calm but critical thought is needed.

2. The future of music education is not determined solely by its technologies. The twin dangers of assuming too much or too little are evident if one looks back at the impact of technology on different fields. Although our history is saturated by stories of unfulfilled visions (e.g., a paperless world), it is also dominated by stories of visions being realized more quickly than anticipated (e.g., the human genome project). Technological determinism in any form within music education is worth avoiding as we seek to develop our pedagogy. Facer and Sandford comment that
the sociology of technology, actor network theory, socio-cultural psychology, and post-structural critical theory, however, all make visible the complex relationship between technological development and social change. Although there are different positions on this spectrum, these perspectives imply an understanding of social change as a co-production of technical, discursive and social factors. (Facer \& Sandford, 2010, pp. 76-77)

Within the field of music education it is worth dwelling on this notion of co-production and the factors that it contains. Considering music education in isolation from other educational, technical, and sociological dimensions will not be a helpful approach. Whilst the discrete elements of music as a subject culture may be possible to define, their implications and connections with wider fields of knowledge, including the socio-technological field, need to be acknowledged and strengthened if change is to occur in a systematic and helpful way. There needs to be a firm emphasis on music education with technology engaging with and relating to wider educational theories and activities. Too narrow a focus on the technology itself will not provide the answers.

3. Music education has a range of responsibilities that relate closely to broader educational agendas. As music educators, where do our responsibilities lie? The Beyond Current Horizons program conceptualized education as being responsible for:

- Qualifying learners to take on certain roles (requiring the development of knowledge and competencies)

- Socializing learners to participate in wider community, family, and social contexts

- Equipping learners to develop their own sense of selves, identity, and agency (DCSF \& Futurelab, 2009, p. 18)

These aims are very similar to other pieces of recent curriculum reform and development, such as the recent implementation of the new Key Stage 3 (pupils aged 11-14) National Curriculum within England (QCA, 2007, p. 7). A detailed 
exposition of the aims and purposes of music education can be found elsewhere in this handbook. Here, the key point is simple. When one is thinking about the future of music education and the development of new technologies within this, it is important to consider how the broader changes both within and outside music education might relate to these proposed changes and how these may lead us to question and challenge our assumptions about the wider purposes of education (see principle 1 above). Examples here might include how technology implicates the processes of personal and social interaction within musical activities or how creativity and imagination are developed within musical composition.

4. Thinking about the future for music education with technology always requires analyzing associated values, politics, and rhetorical devices. Conceptions or visions of the future are powerful rhetorical devices (Facer \& Sandford, 2010, p. 77). Within the field of music education and technology, it is possible for individuals or groups to use these devices to promote change for various reasons. Perhaps the most obvious examples relate to commercial interests of music technology companies. Whilst many companies may not have an explicit educational rationale underpinning their work, many of them do sell their products into educational markets as part of their wider vision. In this scenario, the rhetoric surrounding the value and use of technological tools in contexts outside of music education are imported into it. One only needs tovisit a small number of schools to see this happening. A recent survey of technology in secondary schools across the United Kingdom (Savage, 2010b) found a prevalence of certain types of hardware and software tools that were designed for uses outside the immediate context of education. This is not to say that these tools cannot (and were not) successfully applied to their educational contexts. Rather, the range of political, commercial, and operational values infused in these technologies through the design and manufacturing process need to be made explicit. They are not neutral. This rhetorical discourse should be made visible, and the consequences of it on the key processes of musical teaching and learning carefully mapped.

These four principles are particularly appropriate for this chapter's focus on preparing for future developments in music education with technology. It is to this area that our attention will now turn.

\section{Future Approaches to Teaching And LeARning in Music With TeChNOlogy}

The principles discussed above are built around the requirement for a careful exemplification of the origins and values underpinning music education with technology. These pieces of technology will change in incredible ways over the next 20 years. Some of these we may be able to predict; others will take us all by 
surprise. But the impact of these new technologies will be dependent upon the social context, value frameworks, educational agendas, and pedagogies that they are brought into and work alongside them. Future curriculum initiatives, such as the development of cross-curricular approaches to teaching and learning, will make different demands on music teachers in their choice and use of these technologies. We will explore these below. But it is vital that we maintain a critical stance in relationship to these issues and do not succumb to false rhetoric. Technologies do not hold all the answers to the potential educational challenges that music educators will face. They are one part of a web of influences on their work. Their use is mediated by other important and powerful factors that need to be held within a careful balance. The relationship between new pedagogical approaches that emerge alongside the use of these new technologies and the role of the technology itself will be a delicate and fragile one that needs to be understood and reflected on within the context of the activity itself. This reinforces the observation made by Lawrence Stenhouse that "there is no curriculum development without teacher development" (Stenhouse, 1980, p. 85). Teachers will by no means be redundant in these future scenarios. Developing that reflective "eye" and "ear" and being alert to the changing nature of their pedagogy will be key skills, whatever new technologies may emerge. Simply coercing music teachers towards certain predetermined positions for the use of music technologies in music education is not the way forward.

With this in mind, I propose to consider four key possibilities or challenges facing music education as new technologies emerge and are applied to processes of teaching and learning. I do not present these as a prescriptive list. I am as uncertain as the next music educator about what the future holds. Rather, I hope that through presenting these issues in light of the key principles above that the reader will be able to begin to thoughtfully anticipate potential changes in music education, and begin to consider how his individual research or pedagogy will develop in light of these changes. I do not present these in any order of importance (although the reason for the order will become apparent as the chapter progresses).

\section{EMPOWERING “TrADING ZONES” AND Redefining Subject Cultures}

For many, the subject culture of music is where their musical identity has been nurtured and developed. Subject cultures contain sets of values, definitions, and interests (Jephcote \& Davies, 2007, p. 210) that, although often hard to define, are experienced by participants within that culture almost intuitively. These values come to the fore when threatened or challenged. For example, evidence of disrupting elements within a subject culture can be seen when insensitive approaches to cross-curricular ways of working are imposed on teachers. In this scenario, 
differences between subject cultures lead to conflict and tension both within and across subjects. It is no surprise, therefore, that this has often been cited as a reason for the lack of cross-curricular development within the secondary curriculum context (Cooper, 1983, p. 208). ${ }^{1}$

Researchers at the University of Bristol investigated how technology can mediate between subject cultures. As a first step, they investigated four major dimensions across which individual subject cultures might differ significantly in respect oftheir relationship with technology. These were:

1. The "sunk costs" of information and communication technologies (ICT) within the subject culture. This refers to the material and symbolic investments teachers have consciously or unconsciously made in conceptions of the content of the subject, its purpose, and how it should be taught in respect of ICT.

2. The modes of learning that ICT might facilitate. This refers to the characteristic processes, demonstrations, and outcomes of learning within the subject culture. Equally taken for granted are what counts as success in the subject, how it is achieved, and how it is known.

3. The relationship to wider contexts. Subject cultures are differently situated in terms of their wider contexts and how they relate to them. The most important of these contexts are the curriculum requirements and the subject's place in the pecking order of the school, both of which may impact critically on their access to and use of ICT.

4. The relationship between technology, pedagogy, and curriculum content. (University of Bristol, 2010a)

These dimensions share many points of similarity with the principles extracted from the Beyond Current Horizons program. The contextualization of technology within wider frameworks or within curriculum, pedagogy, and subject culture is particularly noteworthy. It is worth exploring the musical implications of these dimensions a little. Perhaps difficult and uncomfortable questions need to be asked. In respect of sunk costs, how can we ensure that the future material and symbolic investments we buy into with technology resound clearly with the notions of why music education is important and of value for all young people? In respect of modes of learning, is successful engagement in processes such as musical performance or composition the same when technologies are involved? What are the potential losses or gains within such a process? Is it important that all children learn to play an instrument? What exactly is the different between a traditional instrument and a digital instrument? In respect of issues surrounding pedagogy and curriculum content, to what extent will new technologies take the focus away from the teacher and encourage more informal, independent learning? Should this be encouraged?

The findings of the University of Bristol study are presented online through groupings of materials produced by each Subject Design Team (University of Bristol, 2010b). Key findings from each team pointed to 
the importance of the teacher and the ways in which technology is incorporated into their pedagogy. This emphasises the importance of the ecological setting of classrooms and how a mixture of teachers' subject and pedagogical understandings act as filters during planning, practice and reflection.

(Sutherland \& John, 2005, p. 411)

The role of the teacher was fundamental in incorporating technology within the classroom. But this is not straightforward. John (2005) identifies a range of powerful, historical forces that can mitigate against this:

Much of the current debate around the educational value and purpose of ICT can be set within the "generic" (or pedagogic) modes that have a tendency to functionalise education. This interpretation has led to a "cultures in tension" explanation for the resistance of accepted subject sub-cultures to the incorporation of ICT into their curricular and pedagogic processes. These conflicting rationales have led to a number of explanations including subject resistance (Finlayson \& Perry, 1995), techno-phobia (Selwyn et al., 2001) and "technological colonisation" (Goodson \& Mangen, 1995, p. 626). At the core of this is "cultures in tension," the idea that the particular discourses that have dominated the educational landscape for more than a century and a half have been thrown into sharp relief by the rise of digital technologies. (John,

2005, p. 471)

Clearly, much of the angst is evidence of a lack of thinking in respect of principles 3 and 4 . In the future, if we are to avoid this tension between music education and our use of technology within it, it will be important to find ways to ensure that potentially negative aspects of technological use are minimized, and to ensure that our critical thinking about the purposes and function for music education is kept under constant review. One of the ways that John suggests we can utilize to avoid music education retracting and consolidating within itself is to explore the use of a metaphor to help build bridges between music, technology, and other subject cultures. His metaphor of "trading zones" helpfully examines what he calls the "borderlands" between subjects and technology within which certain types of "transactions" can take place. Using Galison's anthropological work as a starting point (Galison, 1997), John explores the various subject subcultures within physics, analyzing the various trading that takes place between theoreticians, experimentalists, and engineers. He concludes:

Exchanges between sub-cultures can be compared to the incomplete and partial relations which are established when different tribes come together for trading purposes. Each tribe can bring things to the "trading space" and take things away; even sacred objects can be offered up and exchanged. This trading process also gives rise to new contact languages which are locally understood and co-ordinated. (John, 2005, pp. 485-486)

John suggests that the use of this "trading zone" metaphor can help us understand more fully the transitory and evolving relationship between a subject culture and the technologies that are brought to bear on it. The boundary between music education and technology becomes permeable in such a model, with notions of 
success depending on the perceived value associated with the presented ideas, and the way the participants act on these and understand them. John is anticipating an evolutionary space, one in which the every element becomes interdependent:

\begin{abstract}
"Transaction spaces" are evolutionary where the affordances and constraints of the situation, the tools, and the setting can facilitate further interaction as well as limit it. To occupy a "trading zone" does not mean abandoning one's "sacred" disciplinary "home" nor allowing the "profane" to dominate the exchange; rather it respects subtle negotiation and accommodation (Wertsch, 2003; Claxton et al., 2003) processes that encourage multiple and modified identities to emerge over time. (John, 2005, pp. 485-486)
\end{abstract}

Technology-mediated exchanges or interactions of the type John is anticipating are something that music educators should aspire to develop in their work with technology. As we will see below, at their peak they may lead to opportunities for the emergence and establishment of new musical languages and pedagogies, locally situated and, perhaps, of value and understood only to those directly involved (but no less educationally valuable because of this). But this will only happen when the items or "objects" that are being exchanged are of value. It is worth pausing and pondering what the "sacred objects" of music education are. Are we prepared to offer them up within such an exchange and allow them to be negotiated with or compromised? Looking around educational initiatives today, there are plenty of examples of low-value ("profane") exchanges being done in the transactional space we inhabit. These are characterized by pieces of curriculum development that merge music down to its lowest common denominator, underplaying the well-established strengths of its subject culture and replacing these with hastily constructed and musically meaningless uses of technology which disempower teachers and cut short the opportunities for their students' learning. In contrast, high-value exchanges will result in meaningful developments in music education that center on attributes that underpin ongoing teacher development. As John's conclusions assert:

If this agenda is to materialise then schools and subjects need time to adjust to using ICT, to explore its possibilities and to engage with its affordances as well as understanding its constraints. Additionally, certain conditions need to be prevalent if the further blending of technology and pedagogy within subjects is to flourish. These conditions are dependent on a number of characteristics, all of which, according to Eraut (2000), are regarded as fundamental to the creation of a suitable organisational microclimate. They include:

- A blame free culture;

- Learning from experiences-positive and negative-at both group and individual levels;

- Trying to make full use of the various knowledge resources held by members;

- Encouraging talk about learning;

- Locating and using relevant knowledge from outside the group;

- Enhancing and extending understandings and capabilities of both the group as a whole and its individual members. (John, 2005, pp. 484-485) 
Please note this emphasis on collaboration. We will be coming back to this later in the chapter.

\title{
Developing a New Language of Music
}

\author{
Ears become wired \\ And minds become strong because \\ You're speaking the language, \\ The language of music, \\ The door is now open \\ To learn how to speak.
}

Young's poem (2003), built as it is around key terms and phrases from the United Kingdom's National Curriculum for Music document, is, in itself, a reminder that creativity can be inspired in the strangest of places. Within future, transactional spaces, one hope is that music educators will be able to facilitate and develop a new language of music that, whilst respecting and acknowledging the subject culture that underpins it, is inspired by the greater degree of access and equality of opportunities that new technologies can bring. Alex, a sound designer from south Manchester, first alerted me to this new, technologically inspired musical language (Savage, 2005b). At the time I had just completed my own Ph.D. studies and had embarked on my first postdoctoral piece of research into the practice and pedagogy of songwriting. I met Alex and interviewed him at his studio, in the basement of his house under the shadow of Old Trafford, the Manchester United Football Club's stadium. ${ }^{2}$ Interviewing Alex was a life-changing moment. Through his use of technology, he had not just opened the door but blasted it off its hinges and learnt how to speak with a musical fluency and passion that was peculiarly infectious. Here was someone whose music education was the exact opposite of mine; no formal qualifications, no instrumental or conservatoire training; no "advanced"level musical studies. Yet his breadth of musical knowledge and experience put my own to shame; his compositional and improvisational abilities were outstanding; his ability to analyze, reflect on, and communicate his musical intentions were breath-taking. What had facilitated these skills in him? What was his source of inspiration? The short answer was "music":

Music is-how can I describe it, it's so many things-it really has saved me from a life that-its hard to explain. I grew up on an estate in Edinburgh and I used to get in quite a lot of trouble. Music saved me from a path that I could see leading to destruction and for that I'm very grateful. So I tend to treat music as a very good friend. It's something that's helped me to communicate with people, to express myself. It's a language that you can relate to people from different nations. It transcends limitations. (Alex, in interview; Savage, 2005b) 
It was interesting that Alex did not respond to this question with the answer "technology." Technology, for Alex, was the tool, a powerful, facilitating tool that allowed him access to the world of music in a way that other tools had prevented. At the time of my initial meetings with Alex, much of his musical language was, in John's terms, "locally understood and co-ordinated" (John, 2005, p. 486). However, in the intervening years, Alex has worked hard on his musical language and has become a leading international sound designer. It has allowed him to transcend the "limitations" of his early educational and musical experiences. Now, Alex is a successful, professional composer and sound designer in a highly competitive commercial market. He speaks an articulate musical language that, importantly, is his own, authentic style (forged through the use of his technological tools).

Music was the key for Alex. But technology played its part, too. As we will see below, ensuring that these two elements remain fused together in an appropriately balanced relationship will be key to ensuring that more young people become passionate about their own musical language.

\section{Relocating Musical Knowledge, Skills, AND UNDERSTANDING}

In preparing for this chapter, I was reflecting on my conversations with Alex. A recurring theme was the way in which technology had allowed him to access the processes of musical performance, composition, and improvisation in new ways. Technology had facilitated an approach to the development of musical knowledge, skills, and understanding but in ways that did not depend on traditional musical assumptions, language, or pedagogies. They had been relocated in his mind. He had approached and engaged with them from a different direction. One of the outcomes of this process was that Alex talked about his music in a language quite different from my own. It was characterized by visual metaphors, by analogies drawn from different art forms (including contemporary cinema and dance) as well as anthropological studies.

John's anthropological approach to the establishment of new languages within trading zones (John, 2005, p.486) is an interesting metaphor through which one could analyze Alex's musical education. The language discourse of music technology is, in itself, highly metaphorical and makes connections across a range of trading zones. As an example, an analysis of language within a typical piece of sequencing software will uncover terminology such as cut, copy, and paste (all of which are found within word processing and video editing software). More widely, metaphorical links between music and art have a long history and have underpinned many cultural movements (Maur, 1999). Alex's inquisitive mind had 
led him to make all kinds of interesting connections of this type. Many of these became inspirations for his compositional work.

Alex's work and John's metaphor lead me to consider to what extent music technology should be a distinct area of study. In many curriculum frameworks within the United Kingdom, students get the opportunity to study either "music" or"music technology." Both areas are underpinned by identifiably discrete, yet artificial, sets of assumptions about the knowledge, skills, and understanding that are important. Personally, I am worried by this degree of separation. For some, it seems to imply an upper and lower tier of musical engagement and perhaps even a degree of snobbery. This is very subtle and often hard to notice. But I think it sounds something like this:

Interviewer: Tell me about your use of music technology in the department...

Teacher 1: We have a range of technology for students who struggle to play a musical instrument. It is about providing them with an opportunity to play and compose music.

Interviewer: What about those students who play a musical instrument?

Teacher 1: Why would they want to use technology? They can play already.

Or this:

Interviewer: How do you decide who gets to study for a $\mathrm{GCSE}^{3}$ in Music?

Teacher 2: The students can choose to do it.

Interviewer: Is that it? Are there any conditions?

Teacher 2: Not really. As long as they can play an instrument to a basic level I'm happy to let them do it.

Interviewer: What do you mean by a "basic level'?

Teacher 2: $\quad$ About Grade $5^{4}$ by the time they get to the end of Year 11. That's the standard the exam board sets.

Interviewer: Really? What about music technology? Can they use that instead?

Teacher 2: No, that's not really the same is it? They can use that as well but perhaps it is better covered in other courses we run.

(Both interviews were conducted by the author as part of a research and development project funded by the Training \& Development Agency; reported in Savage, 2007).

To my mind, there should be no distinction between music and music technology as areas of knowledge and practice. Future approaches to music education with technology need to be placed firmly alongside traditional music studies. There is no difference. Having established this, musical studies need to be placed more firmly within a cross-curricular approach to teaching and learning. This is not about watering down a subject culture through bland and mediocre curriculum 
collaborations. It is about individual teachers developing powerful, cross-curricular pedagogies that are outward looking, underpinning by a centrifugal perspective (Savage, 2010c). It will see individual teachers wanting to maximize the opportunities for contextualizing musical learning within a broader framework of teaching and learning, and responding positively to the new affordances of technological tools in ways that enhance, enrich, and extend traditional approaches within their subject culture. This moves us on to my final point.

\section{Facilitating Educational Collaborations}

From this powerful base, individual teachers can engage in meaningful collaborations with teachers within their subject cultures and, importantly, those outside. One of the key future challenges facing educational communities will be the creation of opportunities for teachers to debate and discuss the educational purposes for, and philosophy underpinning, new technological approaches to teaching and learning. Teachers need to have a meaningful say in this ongoing debate, challenging and critiquing ideas so that the future shape of curriculum initiatives have a greater degree of shared ownership and, it is hoped, a wider impact. Facer calls this a "curriculum for networked learning" and defines it as "enabling individuals to learn to work effectively within social networks for educational, social and civic purposes and to develop strategies to establish and mobilise social networks for their own purposes" (2009, p. 7).

For teachers and learners the degree of personalization within such a network is significant and should allow for the development of powerful processes for the development of subject knowledge and curriculum development. It will also facilitate the cross-subject exchanges or transactions that we have been discussing. From the perspective of the learner (and this would include teachers as well as students), such a curriculum might comprise of opportunities for:

- Learning and working within meaningful sociotechnical networks not wholly within single educational institutions

- Being assessed in interaction with tools, resources, and collaborators

- Developing capacities to manage information and intellectual property, building reputation and trust, developing experience of working remotely and in mediated environments

- Creating new, personalized learning networks

- Reflecting on how learning is connected with other areas of personal, social, and working lives, as well asmanaging and negotiating these relationships

- Exploring the human-machine relationships involved in sociotechnical networks (Facer, 2009, p. 7) 
The days of the individual teacher, teaching their individual subject in their own classroom, with the door closed to the majority of others outside, are clearly numbered. Key technological developments have already facilitated a significant shift in individual subject cultures, curriculum design, and delivery. The role of technology within teaching and learning is powerful. Allying technology to the promotion of a cross-curricular approach to teaching and learning makes sense in many ways, not least in the educational benefits that it brings to students and teachers and the way that it reflects the wider use of technology outside the world of education. Networking and collaborative approaches are a key way forward.

\section{Conclusion}

Change is now a constant condition in our education system, reflecting changes in the wider world. This has implications for teacher identity and role. What sort of teacher development is needed in order to keep pace with such change? We have to ask ourselves whether we want a mere "retooling" of teacher competencies for specific purposes, or an approach that supports a renaissance in teacher development for an uncertain future. This is not about making an industrial process more efficient; rather, it is about enabling cultural change in the profession (Futurelab, 2006, p. 39).

What will the future of music education look like? How will the use of technology shape and mediate the educational processes that underpin it? It would be a bold writer who would predict, with any certainty, the changes and technological developments that our educational futures will contain. This chapter has not focused on this type of guesswork (educated or otherwise). But some things seem certain. Technological change continues to move at a fast pace. Earlier in the chapter we considered the Beyond Current Horizons research project. We looked together at some of the key principles that informed the research, arguing that they were good foundations for our work in re-imagining the use of technology within music education. I argued that future implementations of technology in music education require us to make continued challenges to the assumptions of music education, whether they are related to the philosophy or practice of music education. Technological determinism should be avoided at all costs. Future pedagogies of music education with technology need to connect to the broader aims and responsibilities of education generally and musically. Similarly, technological rhetoric is unhelpful and creates divisions in educational approaches that we should be seeking to heal.

Beyond Current Horizons is supported by a set of online resources (DCSF \& Futurelab, 2009). A central plank in these is the modeling of various educational scenarios. These scenarios "are stories of three different possible futures, imagining how the world could look after 2025, in order to challenge assumptions and 
stimulate thinking about the present" (DCSF \& Futurelab, 2009). The scenarios are structured around three different, potential worlds. Each of these worlds has a different set of social values. These include increasingly individualized, increasingly collective, or increasingly contested approaches towards life and education. Reading through these scenarios is a very worthwhile activity. The key questions at the end of this chapter will help you do this and apply aspects of these scenarios to music education.

The Futurelab report quoted above argues for a change in approach for teachers' professional development with technology. It acknowledges that the processes by which teachers learn about new technologies are complicated and constricted in various ways. But

the possibilities for real change in the system do exist. If we can bring the technologies into situations that resonate strongly with teachers' sense of professional and moral purposes, we may yet see what might truly prove to be a renaissance, in which teachers would employ digital technologies for 'understanding, reflection, ingenuity and creativity,' and, through these, support their own learning in new ways. (Futurelab, 2006, p. 41; italics added)

The best chances of technology having a positive educational impact lie with teachers aligning these powerful tools to their own sense of professional purpose. One could say that there will be no technological development without teacher development. The writers' suggestion is that as teachers' own learning is supported through a more cohesive system, they will become more adept at creating interesting opportunities for learning with and through digital technologies for their students.

The classification of natives and immigrants within the digital revolution (Prensky, 2001, pp. 2-3) is well known. Digital natives "speak the digital language of computers, video games and the Internet," whilst digital immigrants have been "fascinated by and adopted many or most aspects of the new technology but always retain, to some degree, their 'accent,' that is, their foot in the past" (Prensky, 2001, pp. 1-2). Whilst research suggested that many teachers see themselves as competent in this area (Savage, 2007), a large number continue to struggle not just in the development of their own skills with ICT but also in applying these within curricula contexts (Savage, 2010b). The individualization of music education within our schools means that there are few opportunities for the collaborative and networking required to initiate and sustain meaningful change. Music education with technology, in this context, faces a continued danger of localization and colloquialism. However, the broad notions of digital immigrant and digital native are too simplistic. Studies by Bennet, Maton, and Kervin (2008) have shown that there might be as much variation in technology use within the generation defined as digital natives as those that could be found between the generation of digital natives and digital immigrants. Within music education, Salavuo has discussed similar issues (Salavuo, 2008). During the course of completing a recent piece of research, I presented some of these ideas to a group of students who were completing their course of initial teacher education. A lively discussion ensued during which one 
student responded that he did not feel like a digital native or a digital immigrant. He felt like a digital "expat." Afterward, when questioned further, he wrote:

I go somewhere digital, stay there and never get to know the surrounding areas. Definitely room for cyber improvement where this inexperienced little piggy is concerned. What I don't know may injure me in schools in the upcoming weeks. (Savage, 2009)

This highlights another obvious danger. Digital "expats" can find comfort in their digital surroundings and may find it difficult to move on, too. The dangers of complacency are just as real for the digital native as they are for the digital immigrant.

\section{Reflective Questions}

1. It is wise to look ahead, but as Churchill asserts, it is difficult to look further than you can see. What tools can you adopt to aid your ability to see further? To what extent have the tools contained within this chapter aided your sight?

2. There is a balance between looking backward and looking forward. One of the chapter's key assertions is that future actions need to be contextualized within a clear understanding of wider frameworks and assumptions. To what extent does your knowledge of present-day educational contexts and the assumptions that underpin them prepare you for future applications of technology within music education?

3. What is the imprint of technology on music education?

4. What are the elements of music's subject culture that facilitate or constrain the adoption of technological tools within it? What is sacred within music education and can technology touch this in any way?

5. Collaborations are powerful but difficult to sustain. To what extent can new models of collaboration within music education be facilitated? What role can technology play in helping build new, meaningful collaborative networks?

6. Having read the chapter, what are your thoughts about a possible, probable, or preferred model of music education with technology in the future?

\section{KEY SOURCES}

Facer, K. (2009). Educational, social and technological futures: A report from the beyond current horizons programme. London: DCSF \& Futurelab. 
Facer, K., \& Sandford, R. (2010). The next 25 years? Future scenarios and future directions for education and technology. Journal of Computer Assisted Learning,26, 74-93.

John, P. (2005). The Sacred and the Profane: Subject sub-culture, pedagogical practice and teachers' perceptions of the classroom uses of ICT. Educational Review, 57(4), 469-488.

Savage, J. (2010). Cross-curricular teaching and learning in the secondary school. London: Routledge.

\section{WEBSITES}

Department for Children Schools and Families (DCSF)\& Futurelab (2009). Beyond current horizons. http://www.beyondcurrenthorizons.org.uk/ [accessed July 7,2009 ].

Education Futures Timeline. http://www.educationfutures.com/resources/timeline/. Futurelab. (2006). Teachers' learning with digital technologies: A review of research and projects. Bristol: Futurelab. Available at http://www.futurelab.org.uk/resources [accessed October 20, 2009].

The Future of Education. http://www.futureofeducation.com/.

\section{NOTES}

1. It is also interesting to note, however, that more recent research in this area has identified that excellence in teacher's subject knowledge is one of the key attributes for successful developments of cross-curricular teaching and learning (CIDREE, 2005).

2. The Old Trafford ground is, rather appropriately to this context, often referred to as the "theatre of dreams."

3. The GCSE is a General Certificate in Secondary Education, normally taken by students at the end of Year 11 (age 15-16) in the UK educational system.

4. Grade 5 refers to a particular level within the instrumental examination system run by groups such as the Associated Boards of the Royal Schools of Music within the United Kingdom.

\section{REFERENCES}

Apple. (2009). http://www.apple.com/iphone/appstore/ [accessed March 20, 2009].

Bell, W. (1997). Foundations of futures studies. London: Transaction Publishers.

Bennet, S., Maton, K., \& Kervin, L. (2008). The "digital natives" debate: A critical review of the evidence. British Journal of Educational Technology, 39(5), 775-786.

Cain, T. (2004). Theory, technology and the music curriculum. British Journal of Music Education 21(2), 215-221. 
CIDREE. (2005). Cross-curricular themes in secondary education: Report of a CIDREE collaborative project. Sint-Katelijne-Waver (Belgium), CIDREE. Available at www. cidree.be/uploads/documentenbank/4854365076a88c8ba93cbebeo4fd9196.pdf [accessed July 20, 2009].

Claxton, G., Pollard, A. \& Sutherland, R. (2003). Fishing in the fog: Conceptualising learning at the confluence of cultures. In R. Sutherland, G. Claxton,\& A. Pollard (eds.), Learning and teaching: Where world views meet (pp. 1-13). London: Trentham Books.

Cooper, B. (1983). On explaining change in school subjects. British Journal of Sociology of Education, 4(3), 207-222.

DCSF \& Futurelab. (2009). Beyond current horizons. http://www.beyondcurrenthorizons. org.uk/ [last accessed 24/7/09].

Draper, P. (2008). Music two-point-zero: Music, technology and digital independence. Journal of Music, Technology and Education, 1(2-3), 137-152.

Facer, K. (2009). Educational, social and technological futures: A report from the beyond current horizons programme. London: DCSF \& Futurelab.

Facer, K., \& Sandford, R. (2010). The next 25 years? Future scenarios and future directions for education and technology. Journal of Computer Assisted Learning, 26, 74-93.

Federation of Music Services (FMS). (2010). Wow, it's music next. Full report available from http://www.thefms.org/ [last accessed 1/2/10].

Fitzsimmons, C. (2009, March 13). Government outlines digital rights agency proposal. Guardian. http://www.guardian.co.uk/media/2009/mar/13/uk-government-outlinesdigital-rights-agency [accessed March 20, 2009].

Futurelab. (2006). Teachers' learning with digital technologies: A review of research and projects. Bristol: Futurelab. Available at http://www.futurelab.org.uk/resources [accessed October 20, 2009].

Galison, P. (1997). Image and logic: The material culture of micro-physics. Chicago: University of Chicago Press.

Goodson, I. F., \& Mangen, J. M. (1998). Subject cultures and the introduction of classroom computers. In I. F. Goodson (ed.), Subject knowledge: Readings for the study of school subjects (pp. 105-121). London: Falmer Press.

Graham, F. (2009). Disability no barrier to gaming. BBC News, http://news.bbc.co.uk/1/hi/ technology/7935336.stm [last accessed 20/3/o9].

Jenkins, H., Purushotma, R., Clinton, K., Weigel, M., \& Robison, A. J. (2007). Confronting the challenges of participatory culture: Media education for the 21stcentury. An occasional paper on digital media and learning. Chicago: MacArthur Foundation.

Jephcote, M., \& Davies, B. (2007). School subjects, subject communities and curriculum change: The social construction of economics in the school curriculum. Cambridge Journal of Education, $37(2), 207-227$.

John, P. (2005). The sacred and the profane: Subject sub-culture, pedagogical practice and teachers' perceptions of the classroom uses of ICT. Educational Review 57(4), 469-488.

Maur, K. (1999). The sound of painting: Music in modern art. London \& New York: Prestel.

Ofsted. (2009). Making more of music. London: Ofsted. Available at http://www.ofsted. gov.uk/Ofsted-home/Publications-and-research/Browse-all-by/Documentsby-type/Thematic-reports/Making-more-of-music-an-evaluation-of-music-inschools-2005-08.

Prensky, M. (2001). Digital natives, digital immigrants. On the Horizon, NCB University Press, 9(5), 1-6.

QCA. (2007). The national curriculum: Statutory requirements for key stages 3 and 4 . London: QCA. 
Reimer, B. (1994). Is musical performance worth saving? Arts Education Policy Review, 95(3), 2-12.

Salavuo, M. (2008). Are university students digital natives? http://weblog.siba.fi/ msalavuo/2008/09/12/are-university-students-digital-natives/ [accessed March 20, 2009].

Savage, J. (2010a). New report on the "benefits" of instrumental learning. http://jsavage.org. $\mathrm{uk} / \mathrm{p}=539$ [accessed February 1, 2010].

Savage, J. (2010b). A survey of ICT usage across English secondary schools. Music Education Research,12(1), 47-62.

Savage, J. (2010c). Cross-curricular teaching and learning in the secondary school. London: Routledge.

Savage, J. (2009). Are you a digital native? http://jsavage.org.uk/?p=202?more-202 [accessed March 20, 2009].

Savage, J. (2007). Reconstructing music education through ICT. Research in Education, 78 , 65-77.

Savage, J. (2005a). Is musical performance worth saving? http://www.music-ite.org.uk/files/ articles/musical-performance.pdf [accessed February 1, 2010].

Savage, J. (2005b). Information communications technologies as a tool for re-imagining music education in the 21st century. International Journal of Education \& the Arts, 6(2). http://ijea.asu.edu/v6n2/.

Savage, J. (2004). Working towards a theory for music technologies in the classroom: How students engage with and organise sounds with new technologies. British Journal of Music Education, 22(2), 167-180.

Somekh, B. (2007). Pedagogy and learning with ICT. London: Routledge.

Spear, M., Gould, K., \& Lee, B. (2000). Who would be a teacher? A review of factors motivating and demotivating prospective and practising teachers. Slough, UK: NFER.

Stenhouse, L. (1980). Curriculum research and development in action. London: Heinemann Educational.

Sutherland, R., \& John, P. (2005). Affordance, opportunity and the pedagogical implications of ICT. Educational Review, 57(4), 405-413.

University of Bristol (2010a). InterActive Education Project: Subject cultures. http://www. interactiveeducation.ac.uk/sub_cult.htm [accessed January 8, 2010].

University of Bristol (2010b). InterActive Education Project: Learning. http://www. interactiveeducation.ac.uk/learning.htm [accessed January 8, 2010].

Van Manen, M. (1977). Linking ways of knowing with ways of being practical. Curriculum Inquiry, 6(3), 205-228.

Wertsch, J. (2003). Dimensions of culture-clash. In R. Sutherland, G. Claxton, \& A. Pollard (eds.), Learning and teaching: Where world views meet (pp. 273-282). London: Trentham Books.

Young, M. (2003). The language of music. On Yamaha Kemble \& Virtual Learning Environments Foundation Found Sound (CD-ROM). www.foundsound.org [accessed January 5, 2005]. 
